\title{
An Electrical and Computer Startup Kit for Fundamentals of Engineering (FE) Exam
}

\section{Dr. Mohammad Rafiq Muqri, DeVry University - Pomona}

Dr. Mohammad R. Muqri is a Professor in College of Engineering and Information Sciences at DeVry University. He received his M.S.E.E. degree from University of Tennessee, Knoxville. His research interests include modeling and simulations, algorithmic computing, analog and digital signal processing.

\section{Dr. Javad Shakib, DeVry University - Pomona \\ Hasan Muqri \\ Dr. Moe Saouli, DeVry University - Pomona}

Twenty five years industry and academe experience, in public, for profit, and non- profit sectors. Background in engineering, program and project management, managed manufacturing and industrial engineering departments and teams in the aerospace, electronics and telecom industries. Educator, with experience managing departments, programs, research and teaching undergraduate and graduate, business administration and general education courses. Authored, published and presented research papers in conferences, peer reviewed journals, with multidisciplinary interests in technology, business, quality systems, organizational leadership and education. 


\title{
AN ELECTRICAL AND COMPUTER STARTUP KIT FOR FUNDAMENTALS OF ENGINEERING (FE) EXAM
}

\begin{abstract}
Many engineering technology students find the electrical and computer engineering sections of the general Fundamentals of Engineering (FE) exam to be the most challenging. This paper attempts to present the development and application of a practical teaching module to assist students with the first step of the process that leads to the P.E. license. This module is aimed to furnish the extra review and practice which technology students need to meet this challenge through a concise review of the electrical and computer topics covered on the FE exams.
\end{abstract}

The knowledge base comprises of eighteen subject areas: namely Mathematics, Probability and Statistics, Ethics and Professional Practice, Engineering Economics, Properties of Electrical Materials, Engineering Sciences, Circuit Analysis, Linear Systems, Signal Processing, Electronics, Power, Electromagnetics, Control Systems, Communications, Computer Networks, Digital Systems, Computer Systems and Software Development.

This paper will explain how this in-house learning and teaching module was instrumental in progressive learning for students by presenting them the key concepts and general theory that encompass the demanding subject areas. These students first took a diagnostic pre-test; after, they underwent rigorous prep that was followed by a FE post-practice exam. This module helped students reinforce the fundamentals and helped them score higher on this examination. Finally, the results of the survey analyzing this learning methodology will also be discussed.

This will go a long way in motivating technology students to take this important, professional exam, eliminating their fear, improving their understanding, and reinforcing the best practices for life-long learning

Introduction

The Fundamentals of Engineering (FE) exam is typically the first step in the process leading to the P.E. license. It is designed for recent graduates and students who are close to finishing an undergraduate engineering degree.

The National Institute for Certification of Engineering Technologies (NICET, a division of National Society of Professional Engineers (NSPE)) defines technologists ${ }^{1}$ as follows: "Engineering technologists are members of the engineering team who work closely with engineers, scientists, and technicians. Technologists have a thorough knowledge of the equipment, applications, and established state-of-the-art design and implementation methods in a particular engineering area."

The Engineering Technology Accreditation Commission (ETAC) of ABET accredits both twoyear AS programs, educating engineering technicians, and four-year BS programs, educating engineering technologists. Typically a four-year engineering technology programs have historically ranged from algebra-based curricula to more rigorous calculus-based curricula, some 
of which are difficult to distinguish from engineering curricula. Recent changes in ETAC accreditation technology have characterized mathematics requirements for all ETAC programs going forward as "differential and integral calculus or other mathematics above the level of algebra and trigonometry."

\section{Licensing Issues}

How do we currently license BS-level engineering technologists in the U.S.? The issues pertaining to the licensure of engineering technologists as professional engineers in the U.S. is a matter that is not often discussed in the engineering profession. It is actually controversial among some professional engineers and engineering technologists.

The NCEES Model Law and Model Rules require a BS degree from an Engineering Accreditation Commission (EAC) of ABET-accredited program or equivalent. There is no mention of ETAC of ABET-accredited programs. The Model $\mathrm{Law}^{3}$ is silent on this issue. The NCEES requirements for the equivalency evaluation of non-ABET accredited programs state, "engineering technology courses cannot be considered to meet engineering topic requirements." Some state boards have interpreted a program's ETAC of ABET accreditation as demonstrable proof that it is not the equivalent of an EAC of ABET-accredited degree, or the program would have applied for EAC accreditation. Since the Model Law does not include provisions for licensing engineering technologists, it has been and is the purview of the engineering licensing board in each jurisdiction.

An NCEES position statement recommends if states do choose to provide a pathway for licensure of engineering technologists, then additional years of engineering experience be required. Historically, jurisdictions have either chosen not to allow licensure of engineering technologists as professional engineers, or, in many cases where there are such provisions, they have required additional years of progressive engineering experience prior to approving an applicant to sit for the PE examination. There are no jurisdictions that license engineering technologists separately.

It appears that engineering licensure practices in the U.S. are such that engineering technologists cannot obtain a license to practice as a professional engineer in $1 / 3$ of jurisdictions, but are capable of obtaining a PE license in the other $2 / 3$ of states if they pass both the FE and PE exams, although they are typically required to have more years of traditional, progressive engineering experience than is required of ordinary engineers.

\section{FE/EIT Resources}

The FE exam is the only uniform, nationally used exam that tests candidates on the material covered in college engineering degree programs. For educators and administrators, the exams have the potential to provide a wealth of information about the relative strengths and weaknesses of students in a program.

The NCEES FE Reference Handbook ${ }^{4}$ is the only reference material that can be used during the exam. It is provided on screen electronically during the exam. It is also available for purchase as 
a hard copy and for free download electronically on the NCEES website.

Nearly 300 Pearson VUE test center locations are available throughout the United States. The examinees can locate the specific sites near their institution by referring to the proper NCEES website at the specific URL.

An exam fee of $\$ 225$ is payable directly to NCEES during the registration process. Some licensing boards may require examinees to file a separate application and pay an application fee as part of their approval process in order to be qualified for seating for an NCEES exam. FE exam results are typically available 7-10 days after one takes the exam. The examinees receive an email notification from NCEES with instructions to view their results in their MyNCEES account. Results include information specific to your licensing board regarding how you should proceed based on your performance.

NCEES offers free institutions reports that break down the performance of students and graduates from their programs, comparing results on specific content areas to national averages. Many engineering departments use these reports to assess program outcomes The new Structure of FE Prep Course

The FE is a computer-based exam that is administered year- round at NCEES-approved Pearson VUE test centers. As of 2014, the FE is offered in the following seven disciplines. The exam lasts over 6 hours, has 110 multiple-choice questions ${ }^{5}$ and is divided according to the specific discipline:

FE Chemical

FE Civil

FE Electrical and Computer

FE Environmental

FE Industrial

FE Mechanical

FE Other Disciplines

The approximate six hours duration includes a nondisclosure agreement, tutorial ( 8 minutes), the exam (5 hours and 20 minutes), and a scheduled break (25 minutes).

\section{Setting up FE/EIT Teaching Module}

Under the guidance of the associate academic dean of affairs, five full time faculty members teamed up for setting up the FE/EIT Module. It was a painstaking task. The author had partial access to some of the resources which were previously used for FE/EIT prep by the following universities:

Auburn University, Alabama

Kansas State University

Southern Methodist University

Georgia Tech, University

Colorado School of Mines 
UCLA Samuel School of Engineering and Applied Science

Most of them were either proprietary or more relevant for the other six specific disciplines like Civil, Mechanical, Industrial, Chemical, Environmental, FE Other disciplines and not so much for FE Electrical and Computer. The author thus resorted to the latest FE/EIT text books and the NCEES offered computer-based practice exams that contain questions and solutions from past exams because they were expected to simulate the real format, style, and level of difficulty.

In addition to NCEES computer based tests ${ }^{6}$ we also used the following textbooks ${ }^{7}$ resources to prepare our Pre and Post Diagnostic exam and weekly quizzes:

FE/EIT Sample Examinations, $2^{\text {nd }}$ Edition By Michael R. Lindberg PE

FE Review Manual: Rapid Preparation for the Fundamentals of Engineering Exam, $3^{\text {rd }}$ Edition By Michael R. Lindberg PE

Electrical Discipline-Specific Review for the FE/EIT Exam ${ }^{13}, 2^{\text {nd }}$ Edition by Robert Angus PE and Michael R. Lindberg PE

Electrical and Computer PE Sample Examination, $2^{\text {nd }}$ Edition by John A. Camara PE

To facilitate the delivery of FE/EIT Prep Module, it was divided into eight study modules the details of which is illustrated in the Table I.

\begin{tabular}{|l|l|l|l|}
\hline $\begin{array}{l}\text { Week 1 } \\
\text { Module I }\end{array}$ & $\begin{array}{l}\text { Week 3 Module } \\
\text { III }\end{array}$ & $\begin{array}{l}\text { Week 5 } \\
\text { Module V }\end{array}$ & $\begin{array}{l}\text { Week 7 } \\
\text { Module VII }\end{array}$ \\
\hline Sept. 5th & Sept. 19th & October 3rd & October 17th \\
\hline $\begin{array}{l}\text { Circuit } \\
\text { Analysis } \\
(10-15)\end{array}$ & $\begin{array}{l}\text { Signal Processing } \\
(5-8)\end{array}$ & $\begin{array}{l}\text { Power } \\
(8-12)\end{array}$ & $\begin{array}{l}\text { Probability and } \\
\text { Statistics } \\
(4-6)\end{array}$ \\
\hline $\begin{array}{l}\text { Linear } \\
\text { Systems (5- } \\
8)\end{array}$ & $\begin{array}{l}\text { Electronics } \\
(7-11)\end{array}$ & $\begin{array}{l}\text { Computer Systems } \\
(4-6)\end{array}$ & $\begin{array}{l}\text { Properties of } \\
\text { Electrical } \\
\text { Materials } \\
(4-6)\end{array}$ \\
\hline & & $\begin{array}{l}\text { Control Systems } \\
(6-9)\end{array}$ & \\
\hline $\begin{array}{l}\text { Week 2 } \\
\text { Module II }\end{array}$ & Week 4 Module IV & $\begin{array}{l}\text { Week 6 } \\
\text { Module VI }\end{array}$ & $\begin{array}{l}\text { Week 8 } \\
\text { Module VIII }\end{array}$ \\
\hline Sept. 12th & Sept. 26th & October 10th & October 24th \\
\hline $\begin{array}{l}\text { Mathematics } \\
(11-17)\end{array}$ & $\begin{array}{l}\text { Communications } \\
(5-8)\end{array}$ & $\begin{array}{l}\text { Engineering } \\
\text { Sciences }\end{array}$ & $\begin{array}{l}\text { Ethics and } \\
\text { Professional } \\
\text { Practice } \\
(3-5)\end{array}$ \\
\hline $\begin{array}{l}\text { Digital } \\
\text { Systems (7- } \\
\text { 11) }\end{array}$ & $\begin{array}{l}\text { Software } \\
\text { Development } \\
(4-6)\end{array}$ & $\begin{array}{l}\text { Electromagnetics } \\
(5-8)\end{array}$ & $\begin{array}{l}\text { Engineering } \\
\text { Economics } \\
(3-5)\end{array}$ \\
\hline & $\begin{array}{l}\text { Computer Networks } \\
(3-5)\end{array}$ & & \\
\hline
\end{tabular}

Table 1. FE/EIT Prep Schedule 
As depicted above, each module comprised of approximately five hours duration on 8 Saturdays from 8:30 AM to 1:30 PM. Each session consisted of a two hour lecture with active interaction, a two hour in-class problem session, a half hour for review, and a half hour for lunch. Students were encouraged to study the weekly topics after class so as to be able to review the material in the next session.

The faculty at our university primarily focused on FE Electrical and Computer prep in accordance with the knowledge areas and estimated number of questions as per NCEES guidelines illustrated in Appendix A.

\section{FE/EIT Pre-EIT Diagnostic Test}

Using FE/EIT Sample examinations from NCEES computer based tests and previously mentioned textbooks, we prepared a scaled down mock up version of FE prep diagnostics exam which was offered to our electronic and computer engineering students at local university campuses. Only eight students voluntarily took this computer based diagnostics exam. The result of this mock up exam were alarming; only one student passed this initial mock up exam while the rest were either borderline or failed. They did not perform remotely close to the expectations. The results of this exam ${ }^{2}$ were discussed in detail with students and their failure was eventually attributed to lack of revision of basic concepts and relevant course work, as well as cold start on their part.

It was realized at this point that passing the general Fundamentals of Engineering (FE) examination will tend to pose a challenge for some of the engineering technology students because traditional engineering education includes a significantly more extensive background in both mathematics and the sciences, which leads to a foundational background in engineering science. Furthermore design capability is then built on that math/science/engineering science core foundation. The engineering technology programs on the other hand provides a much more basic background in math and science, with relatively less emphasis on general engineering sciences, and more so with extensive technology and design content in accordance with general notion that engineering technology students are trained to apply technologies to design in a more hands-on fashion.

In light of recommendations from industrial advisory board meetings, the regular curriculum updates of our university curricula has been constantly revised not for the FE exam, but rather to stay in conformance with TAC of ABET accreditation criteria. Our capstone senior projects and two review courses were introduced earlier to train our technology students to analytically apply the theory and practical applications of math, science, and engineering science to the development and design of electronic and computer systems.

\section{Course Delivery Challenges}

Since the FE/EIT course was delivered on Saturdays, during the regular school session, the number of students who attended this module was not consistent. The number of students who attended regularly was never more than ten. A few junior students invited by the instructor for feedback purposes used to attend, but not for whole duration. Out of the eight students who took 
the FE/EIT Pre-Diagnostics exam, not all attended every Saturday due to some family emergencies. To make up for these students, a few faculty members covered the material for them on Wednesday afternoon after the regular class meeting with them, as they happened to take other courses with them.

As referenced in Appendix A, there are eighteen different Electrical Discipline-Specific FE/EIT Exam knowledge areas which are further divided into other sub topics. It was noticed that the following sub topics were not covered in depth in our curriculum and as such required additional coaching on part of our faculty.

Mathematics - Discrete Mathematics

Probability and Statistics

Properties of Electrical Materials

Electronics - Semiconductor and Solid State Physics

Electromagnetics - Maxwell Equations

The FE/EIT Prep course was offered as a special topics course which is one way new courses are piloted locally at our university campus. This course was instrumental in the progressive learning of the students by relating and applying fundamentals of circuit analysis, analog and digital electronics, micro- computing, power electronics, control systems, signal processing, electro-mechanics, and various energy and material concepts to electronics and computer systems.

The continuous examination of the evolving needs of our students and employers for careeroriented, higher education programs is our university's mission and purpose. Agencies accrediting our programs are also increasingly focused on student outcomes and achievement. Student outcomes are the skills and abilities students are expected to demonstrate at graduation. Some of the student outcomes in our program is the ability to conduct standard tests and measurements; to conduct, analyze, and interpret experiments; and to apply experimental results to improve computer systems and processes.

\section{Application of FE Exam Results}

Effective outcome assessment requires a set of tools to evaluate various aspects of the educational experience. Ideally at least some of these tools should enable comparison with other institutions if they are to have any value as benchmarks or credibility on an objective basis. Prior to beginning the use of the exam for assessment purposes, the engineering faculty at our school conducted meetings to discuss and determine the expected performance in each topic area which was expected to depend on the emphasis of that topic in the electronics and computer engineering program at our university.

A review of the literature revealed that the following two methods ${ }^{8}$ have been promoted by NCEES: the Ratio Method and the Scaled Score Method.

The Ratio Method is essentially a simple process for evaluating exam results by comparing the institution's results with national average by topic in a simple ratio. 
Ratio score $=$ Program Performance Index./National Performance Index

The scaled score on the other hand was developed to allow institutions to present the data in a form that represents the number of standard deviations above or below the national average for each topic as compared to the percentage above or below the national average given by the ratio method. Table 2, below depicts the $\mathrm{NCEES}^{6}$ sample institutional report for FE/EIT exam.

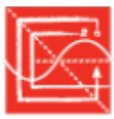

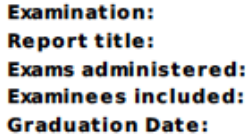

\begin{tabular}{|c|c|c|c|}
\hline \multirow{2}{*}{\begin{tabular}{|l|} 
Name of Institution: \\
Major:
\end{tabular}} & \multicolumn{3}{|c|}{ EXAMPLE } \\
\hline & Civil & FE Examination: & Civil \\
\hline & & Ins & $\begin{array}{c}\text { ABET } \\
\text { Comparator }{ }^{2}\end{array}$ \\
\hline No. Examinees Taking ${ }^{1}$ & & & 2,499 \\
\hline No. Examinees Passing & & & 1,760 \\
\hline Percent Examinees Passing & & & $70 \%$ \\
\hline
\end{tabular}

Fundamentals of Engineering (FE)

Subject Matter Report by Major and Examination

Jul 01-Nov 30, 20xx

First-Time Examinees from EAC/ABET-Accredited Engineering Programs

Exam inees Testing within 12 months of Graduation Date

Uncertainty Range for Scaled

Score 4 $\pm 0.18$

\begin{tabular}{|c|c|c|c|c|c|c|}
\hline & & & & & & \\
\hline & $\begin{array}{l}\text { Number } \\
\text { of Exam } \\
\text { Questions }\end{array}$ & $\begin{array}{l}\text { Institution } \\
\text { Average } \\
\text { Performance } \\
\text { Index }^{3}\end{array}$ & $\begin{array}{c}\text { ABET } \\
\text { Comparator } \\
\text { Average } \\
\text { Performance } \\
\text { Index }\end{array}$ & $\begin{array}{c}\text { ABET } \\
\text { Comparator } \\
\text { Standard } \\
\text { Deviation }\end{array}$ & $\begin{array}{c}\text { Ratio } \\
\text { Score }\end{array}$ & $\begin{array}{l}\text { Scaled } \\
\text { Score }\end{array}$ \\
\hline Mathematics & 7 & 9.8 & 9.8 & 2.7 & 1.00 & 0.00 \\
\hline Probability and Statistics & 4 & 10.4 & 10.1 & 3.5 & 1.03 & 0.09 \\
\hline Computational Tools & 4 & 10.2 & 9.9 & 3.7 & 1.03 & 0.08 \\
\hline Ethics and Professional Practice & 4 & 12.3 & 11.1 & 3.8 & 1.11 & 0.32 \\
\hline Engineering Economics & 4 & 10.7 & 10.1 & 3.6 & 1.06 & 0.17 \\
\hline Statics & 7 & 10.7 & 9.5 & 2.8 & 1.13 & 0.43 \\
\hline Dynamics & 4 & 10.9 & 10.3 & 3.6 & 1.06 & 0.17 \\
\hline Mechanics of Materials & 7 & 9.7 & 9.7 & 2.5 & 1.00 & 0.00 \\
\hline Materials & 4 & 8.7 & 9.2 & 3.1 & 0.95 & -0.16 \\
\hline Fluid Mechanics & 4 & 10.5 & 10.9 & 3.4 & 0.96 & -0.12 \\
\hline Hydraulics and Hydrologic Systems & 8 & 9.7 & 9.4 & 2.2 & 1.03 & 0.14 \\
\hline Structural Analysis & 6 & 9.7 & 8.9 & 2.5 & 1.09 & 0.32 \\
\hline Structural Design & 6 & 8.4 & 8.9 & 2.6 & 0.94 & -0.19 \\
\hline Geotechnical Engineering & 9 & 9.5 & 9.4 & 2.1 & 1.01 & 0.05 \\
\hline Transportation Engineering & 8 & 9.2 & 9.0 & 2.2 & 1.02 & 0.09 \\
\hline Environmental Engineering & 6 & 8.9 & 8.8 & 2.7 & 1.01 & 0.04 \\
\hline Construction & 4 & 11.5 & 9.5 & 3.7 & 1.21 & 0.54 \\
\hline Surveying & 4 & 8.4 & 8.1 & 3.6 & 1.04 & 0.08 \\
\hline
\end{tabular}

1. $\underline{0}$ examinees have been removed from this data because they were flagged as a random guesser.

2. Comparator includes all examinees from programs accredited by the ABET commission noted.

3. Performance index is based on a $0-15$ scale.

4. These scores are made available for assessment purposes. See the NCEES publication entitled Using the FE as an Outcomes Assessment Tool at http://ncees.org/licensure/educator-resources/.

\section{TERMS AND CONDIT IONS OF DATA USE}

This report contains confidential and proprietary NCEES data. The report itself may not be provided to third parties or used for any purpose other than that contemplated by NCEES and the recipient of this report. The information contained in this report however may be shared with accrediting bodies so long as the report recipient expressly informs the accrediting body that the information is confidential and proprietary and may not be used for any purpose unrelated to the accreditation review of the institution or program in question.

By using any of the information contained in this report the report recipient agrees to respect and be bound by these terms conditions and limitations regarding the use of NCEES data. Your cooperation is appreciated.

Table 2. Sample NCEES Institutional Report of FE/EIT Exam Results 
FE/EIT Pre and Post Diagnostics Test Results Correlation and Regression Method

A careful study of the sample NCEES FE/EIT Institutional report reveals that the FE exam is the only nationally normed ${ }^{5}$ exam addressing specific engineering topics for a specific engineering discipline and is therefore an extremely effective tool for outcomes assessment. The FE exam allows an institution to focus on specific goals in selected topic areas. The detailed reports of performance by subject area provide information that can help evaluate success in achieving the program's outcomes as specified by ABET. Over time, these reports can also help the program document the effect of curriculum revisions, teaching innovations, and other actions taken to improve student mastery of engineering studies.

In general, parametric tests ${ }^{9}$ have requirements about the nature or shape of the populations involved: nonparametric tests do not require that samples come from populations with normal distribution or any other particular distribution. Due to the nature of our diverse student population, a rank correlation method will be described. The rank correlation test, or Spearmen's rank correlation, is a non parametric test that uses ranks of sample data consisting of matched pairs. It is used to test for an association between two variables, so the null and alternate hypotheses are as follows (where $\mathrm{p}_{\mathrm{s}}$ denotes the rank correlation coefficient for the entire population):

$H_{0}: p_{s}=0$ (There is no correlation between the two variables.)

$H_{0}: p_{s} \neq 0$ (There is no correlation between the two variables.)

The notation $r_{s}$ will be used for the Spearman rank relation coefficient so as not to confuse it with the linear correlation coefficient $r$.

\section{Rank Correlation Procedure and Notation}

$\mathrm{n}=$ number of pairs of sampled data

$\mathrm{d}=$ difference between the ranks for the two values within a pair

$r_{s}=$ rank correlation coefficient for sample paired data $\left(r_{S}\right.$ is a sample statistic)

$p_{s}=$ rank correlation coefficient for all the population data ( $p_{s}$ is a population parameter)

\section{Test Statistic}

No ties: After converting the data in each sample to ranks, if there are no ties among the ranks for the first variable and there are no ties among the ranks for the second variable, the exact value of the test statistic can be calculated using this formula ${ }^{10}$ :

$$
r_{s}=1-\frac{6 \sum d^{2}}{n\left(n^{2}-1\right)}
$$

Ties: After converting the data in each sample to ranks, if either variable has ties among its ranks, the exact value of the test statistic can be found by using this formula:

$$
r_{s}=\frac{n \sum x y-\sum x \sum y}{\sqrt{\left(n \sum x^{2}-\left(\sum x\right)^{2}\right) *\left(n \sum y^{2}-\left(\sum y\right)^{2}\right)}}
$$


Table 3 depicted below includes FE/EIT Subject Areas Grade Results Ranked by Pre-Test and Post-Test scores. It includes the difference $d$ and the squares of the differences $\mathrm{d}^{2}$.

The value of the rank correlation coefficient is computed in order to determine whether there is a correlation between the rankings of the Pre-test Subject Areas Grade Results and the rankings of the Post-Test Subject Areas Grade Results using a 0.05 significance level.

Table 3: FE/EIT Subject Areas Grade Results Ranked by Pre Test and PostTest

$\begin{array}{llcll}\text { Subject Area } & \begin{array}{l}\text { Student Pre- } \\ \text { Test Grade } \\ \text { Ranks }\end{array} & \begin{array}{l}\text { Student Post- } \\ \text { Test Grade } \\ \text { Ranks }\end{array} & \begin{array}{l}\text { Difference } \\ \mathrm{d}\end{array} & \mathrm{d}^{2} \\ \text { Linear Systems } & 1 & 1 & 0 & 0 \\ \text { Signal Processing } & 3 & 2 & 1 & 1 \\ \text { Electronics } & 2 & 3 & 1 & 1 \\ \text { Power Systems } & 5 & 7 & 2 & 4 \\ \text { Computer Systems } & 4 & 5 & 1 & 1 \\ \text { Control Systems } & 7 & 6 & 1 & 4 \\ \text { Communications } & 6 & 4 & 2 & 4 \\ \text { Ethics } & 8 & 6 & 2 & 16 \\ \text { Total } & & & & \end{array}$

Following the procedure, the data in the Table 3, are in the form of ranks and the neither of the two variables has ties among ranks, so the exact value of the test statistic can be calculated as shown below using the equations above.

We use $\mathrm{n}=8$ (for 8 pairs of data) and $\sum \mathrm{d} 2=16$ (as shown in Table 2) to get

$$
\begin{aligned}
r_{s}=1-\left(6 \sum \mathrm{d}^{2}\right) / \mathrm{n}\left(\mathrm{n}^{2}-1\right) & =1-\left[6(16) / 8\left(8^{2}-1\right)\right] \\
& =1-[96 / 504] \\
& =0.8095
\end{aligned}
$$

If $\mathrm{n}>30$, critical values are found by the following formula, where the value of $\mathrm{z}$ corresponds to the significance level (for example if $\alpha=0.05, \mathrm{z}=1.96$ ).

$$
r_{s}= \pm \mathrm{z} / \sqrt{n-1}
$$

If $\mathrm{n} \leq 30$, critical values are found by using ${ }^{9}$ the Table for Critical values of Spearman's Rank Correlation.

For our case $\mathrm{n}=8$, so we determine that the critical values are \pm 0.738 (based on $\alpha=0.05$ ) and $\mathrm{n}=8)$.

Because the absolute value of the test statistic $r_{s}=0.8095$ does exceed the positive critical value of 0.738 , we reject the null hypothesis and conclude that there is a correlation It has thus been demonstrated that there is significant correlation between the Pre-test Subject Areas Grade Results and the rankings of the Post-Test Subject Areas Grade results. Subjects appear to better learn the FE/EIT prep material by studying more and going through rigorous practice and testing. 


\section{Student Feedback}

A compilation of feedback was from obtained from four out of eight students enrolled in this FE/EIT Prep course, and two junior students who attended the lectures and class activities but plan to take the exam next year. We hope to see better understanding, and authenticity of this faculty-student interaction, and feedback from the future survey based on a wider range of students which will undoubtedly test the validity of mixed performance in course of taking the actual FE exam and the analysis of its outcome.

The feedback from the student indicates that:

Students gained an appreciation of the extensive background required for FE/EIT prep course. Practice problems on the FE exam puts many concepts in control systems communications, ethics, statistics and signal processing to practical use in a context that has been described as "cool" by the students.

Students gained an appreciation of the natural sciences courses required by our engineering program, particularly physics. Often students reported that the physical concepts related to a particular topic (for example electrostatics, resonance, Amperes Law, and Faraday's Law of electromagnetic induction ) made much more sense after implementing the concept in the context of controls and instrumentation applications.

Students gained an appreciation for the difficulties involved in taking closed book exam under pressure and time constraints.

Students spent a significant amount of time reviewing basic discrete mathematics, probability and statistics, properties of electrical materials, semiconductor physics, Maxwell's equations and power systems thermodynamics, strength of materials, statics, dynamics, and materials sciences.

\section{Summary and Conclusions}

As of writing of this paper, so far only one of our students has taken the FE exam and successfully passed it. The overall performance of the rest of the students in our this first initial course offering and the final mockup FE exam was higher than our expectations as demonstrated by the significant correlation between the Pretest Subject Areas Grade Results and the rankings of the Post-Test Subject Areas Grade results. The Electronic Engineering Students appear to better learn the FE/EIT prep material by studying more and going through rigorous practice, review and testing.

This paper is a study in progress and is a testimony of our passionate, ongoing work of teaching and preparing engineering technology students for the FE/EIT exam. We are making a sincere effort to see them becoming successful in their future career. Licensing, however, is a privilege from a governing body (NCEES); it is not a right. A degree shows that a student has studied the 
field, the license shows that the student is an engineer.

In summary, $\mathrm{FE}$ is a direct method of objective assessment with comparisons of institutional results against national results. Assessment does not utilize pass rates, but how students perform on individual exam areas. The FE exam is one effective assessment tool to be used as part of your institution's full assessment package. Multi-center studies and larger sample size are needed to substantiate study findings in different settings.

\section{Bibliography}

1. National Society of Professional Engineers http://www.nspe.org/resources/blogs/pe-licensing-blog/defining-roles-technologists-and-engineers

2. United States Medical Licensing Examination 2003 USMLE performance data, http://www.usmle.org/step3/default.htm. The National Board of Medical Examiners

3. Licensure of Engineering Technologists http://www.nspe.org/resources/blogs/pe-licensing-blog/licensure-engineering-technologists-parti-current-status

4. NCEES Advancing Licensure for Engineers and Surveyors, http://ncees.org/exams/fe-exam/

5. FE Test Center Locations, http://ncees.org/exams/cbt/testing-center-locations

6. FE Electrical and Computer Online Practice Exam, https://account.ncees.org/exam$\mathrm{prep} / \mathrm{store} / \mathrm{category} / \mathrm{FE} /$ product/fe-electrical-and-computer-online-practice-exam-1

7. Angus, R., B., Lindeburg, M., R., Electrical Discipline-Specific Review for the FE/EIT Exam, Professional Publications, 2015

8. Engineering Tools NCEES, https://ncees.org/wp-content/uploads/2012/11/FEOATPresentation-ASEE-2014-final.pdf

9. Triola, T., F., Essentials of Statistics, Addison Wesley, 2007.

10. Numbers Toolkit : Spearman Correlation, http://web.anglia.ac.uk/numbers/biostatistics/spearman/local_folder/critical_values.html

\section{Appendix A}

\section{Electrical Discipline-Specific FE/EIT Exam Topics}

Knowledge Areas

Number of Questions

1. Mathematics

A. Algebra and trigonometry 
B. Complex numbers

C. Discrete mathematics

D. Analytic geometry

E. Calculus

F. Differential equations

G. Linear algebra

H. Vector analysis

2. Probability and Statistics

A. Measures of central tendencies and dispersions (e.g., mean, mode, standard deviation)

B. Probability distributions (e.g., discrete, continuous, normal, binomial)

C. Expected value (weighted average) in decision making

D. Estimation for a single mean (e.g., point, confidence intervals, conditional probability)

3. Ethics and Professional Practice
A. Codes of ethics (professional and technical societies)
B. NCEES Model Law and Model Rules
C. Intellectual property (e.g., copyright, trade secrets, patents)

4. Engineering Economics
A. Time value of money (e.g., present value, future value, annuities)
B. Cost estimation
C. Risk identification
D. Analysis (e.g., cost-benefit, trade-off, breakeven)

5. Properties of Electrical Materials
A. Chemical (e.g., corrosion, ions, diffusion)
B. Electrical (e.g., conductivity, resistivity, permittivity, magnetic permeability)
C. Mechanical (e.g., piezoelectric, strength)
D. Thermal (e.g., conductivity, expansion)

6. Engineering Sciences
A. Work, energy, power, heat
B. Charge, energy, current, voltage, power
C. Forces (e.g., between charges, on conductors)
D. Work done in moving a charge in an electric field (relationship between voltage and work)
E. Capacitance
F. Inductance

7. Circuit Analysis (DC and AC Steady State)
A. KCL, KVL
B. Series/parallel equivalent circuits
C. Thevenin and Norton theorems
D. Node and loop analysis 
E. Waveform analysis (e.g., RMS, average, frequency, phase, wavelength)

F. Phasors

G. Impedance

8. Linear Systems
A. Frequency/transient response
B. Resonance
C. Laplace transforms
D. Transfer functions
E. 2-port theory

9. Signal Processing
A. Convolution (continuous and discrete)
B. Difference equations
C. Z-transforms
D. Sampling (e.g., aliasing, Nyquist theorem)
E. Analog filters
F. Digital filters

10. Electronics

A. Solid-state fundamentals (e.g., tunneling, diffusion/drift current, energy bands, doping bands, $p-n$ theory

B. Discrete devices (diodes, transistors, BJT, CMOS) and models and their performance

C. Bias circuits

D. Amplifiers (e.g., single-stage/common emitter, differential)

E. Operational amplifiers (ideal, non-ideal)

F. Instrumentation (e.g., measurements, data acquisition, transducers)

G. Power electronics

11. Power
A. Single phase and three phase
B. Transmission and distribution
C. Voltage regulation
D. Transformers
E. Motors and generators
F. Power factor (pf)

12. Electromagnetics
A. Maxwell equations
B. Electrostatics/magneto-statics (e.g., measurement of spatial relationships, vector analysis)
C. Wave propagation
D. Transmission lines (high frequency)
E. Electromagnetic compatibility 
13. Control Systems
A. Block diagrams (feed-forward, feedback)
B. Bode plots
C. Closed-loop and open-loop response
D. Controller performance (gain, PID), steady-state errors
E. Root locus
F. Stability
G. State variables

14. Communications

A. Basic modulation/demodulation concepts (e.g., AM, FM, PCM)

B. Fourier transforms/Fourier series

C. Multiplexing (e.g., time division, frequency division)

D. Digital communications

15. Computer Networks

A. Routing and switching

B. Network topologies/frameworks/models

C. Local area networks

16. Digital Systems
A. Number systems
B. Boolean logic
C. Logic gates and circuits
D. Logic minimization (e.g., SOP, POS, Karnaugh maps)
E. Flip-flops and counters
F. Programmable logic devices and gate arrays
G. State machine design
H. Data path/controller design
I. Timing (diagrams, asynchronous inputs, races, hazards)

17. Computer Systems
A. Architecture (e.g., pipelining, cache memory)
B. Microprocessors
C. Memory technology and systems
D. Interfacing

18. Software Development
A. Algorithms
B. Data structures
C. Software design methods (structured, object-oriented)
D. Software implementation (e.g., procedural, scripting languages)
E. Software testing 